\title{
Repeatability of measurements and sources of variability in tests of cardiovascular autonomic function
}

Gillian P Lawrence, Philip D Home, Alan Murray

\begin{abstract}
Objective-To determine the repeatability and sources of variability of clinical tests of cardiovascular autonomic function.

Design-The commonly used electrocardiographic related tests of autonomic function were studied. Two repeat measurements of all tests were made on all subjects on four separate days over a four week period.
\end{abstract}

Subjects-Ten normal subjects with no known autonomic dysfunction were investigated.

Main outcome measures-These were deep breathing (subject seated and supine), Valsalva manoeuvre, standing up from lying position, and normal relaxed breathing (subject supine). During the tests the electrocardiogram and respiratory pattern were recorded by computer. Beat to beat $R R$ intervals were measured automatically from the electrocardiogram, and from these the results of the tests were calculated.

Results-Variance analysis showed significant between subject variability for all tests $(p<0.005)$, but some tests showed a much smaller relative within subject variability than others. Average repeatability data (within subject SD) for each test were calculated, and included deep breathing sitting (maxmin) $R R$ (46 ms), Valsalva ratio $(0 \cdot 17)$ and lying to standing $R R$ ratio $(0 \cdot 11)$. These compare with between subject SDs of $65 \mathrm{~ms}, 0.38$, and 0.13 respectively, at mean values of $305 \mathrm{~ms}, 1 \cdot 92$, and $1 \cdot 15$ respectively. The data highlighted one subject with the poorest repeatability, whose electrocardiogram turned out on closer inspection to be under atrial rather than sinus control at times. Poor repeatability in the other subjects was related to variability in the respiratory pattern, and in the deep breathing test, repeat variability was significantly correlated $(r=0.79)$ with variability in the respiratory amplitude $(p<0.05)$.

Conclusions-Repeatability data should be available to each laboratory carrying out autonomic function tests. The data provided in this study could be used as a baseline. Poor repeatability highlights the need to re-examine the test procedures, or the test data from specific subjects. Variability of respiratory pattern is associated with poor repeatability, and so careful instructions on respiration should be given to each subject before the tests.

(Br Heart J 1992;68:205-11)

The autonomic nervous system (ANS) controls many body functions and is essential for wellbeing. Impaired autonomic function is associated with clinical abnormalities which include postural hypotension, sleep apnoea, diarrhoea, urinary retention, and impotence. ${ }^{1}$ Diabetic subjects in particular suffer from autonomic dysfunction, and it has been estimated that between $20 \%$ and $40 \%$ have some evidence of damage to the ANS. ${ }^{2}$ Early evidence of autonomic dysfunction is often a reduced cardiovascular response to a stimulus. ${ }^{34}$ Since this reduced response was first documented ${ }^{5}$ a series of simple noninvasive tests have been developed that assess the response of the cardiovascular system to different stimuli. In general the test results enable subjects to be assigned to one of four broad clinical groups ranging from normal to severely impaired. ${ }^{6} \mathrm{~A}$ finer quantitative assessment, however, is important for research and for assessing the likely prognosis of a patient. $^{78}$

Many different stimuli have been used to provoke a cardiovascular response; the most common are deep breathing, the Valsalva manoeuvre, and moving from a lying to a standing position. In various centres the test procedures are carried out differently, in particular with reference to the subject's position and the duration of the stimulus. Table 1 documents the variation in reported test procedures.

Normal ranges for autonomic function tests have been documented, ${ }^{915171922}$ and show an age related decline in variability of heart rate. A wide range of values can be expected for a population of normal subjects at a given age although the expected range for an individual subject is smaller than the range for the subject's age. This is important for any follow up studies in an individual subject, as the better the repeatability of measurements the more readily any significant change in a test result will be identified. Despite the wide use of the tests within the clinical environment, 
Table 1 Variation in test procedures and calculated measurements

\begin{tabular}{|c|c|c|c|c|}
\hline Reference & $\begin{array}{l}\text { Position of } \\
\text { subject }\end{array}$ & $\begin{array}{l}\text { Duration } \\
\text { of test }\end{array}$ & $\begin{array}{l}\text { Calculated } \\
\text { result }\end{array}$ & $\begin{array}{l}\text { Variable } \\
\text { calculated }\end{array}$ \\
\hline 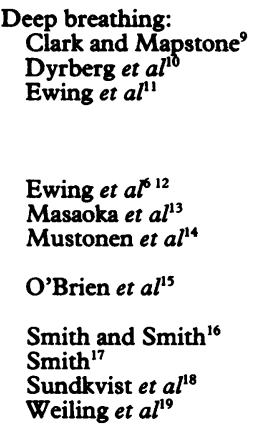 & $\begin{array}{l}\text { Sitting } \\
\text { Sitting } \\
\text { Sitting } \\
\text { Supine/ } \\
\text { semirecumbent } \\
\text { Supine } \\
\text { Supine } \\
\text { Supine } \\
\text { Supine }\end{array}$ & $\begin{array}{l}6 \text { cycles } \\
6 \text { cycles } \\
6 \text { cycles } \\
1 \text { cycle } \\
5 \text { cycles } \\
1 \text { cycle } \\
6 \text { cycles } \\
6 \text { cycles }\end{array}$ & $\begin{array}{l}\text { Mean } 6 \text { cycles } \\
\text { Mean } 5 \text { cycles } \\
\text { Mean } 1 \text { min } \\
\text { Mean } 3 \text { cycles } \\
1 \text { cycle, } \\
\text { Mean } 6 \text { cycles } \\
\text { Mean } 5 \text { cycles } \\
\text { Mean } 6 \text { cycles } \\
\text { Mean } 6 \text { cycles }\end{array}$ & 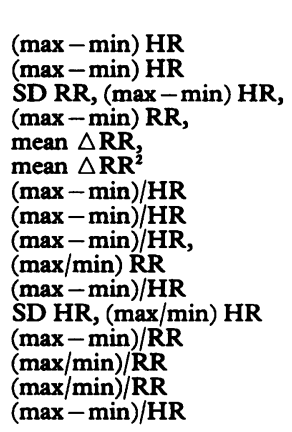 \\
\hline 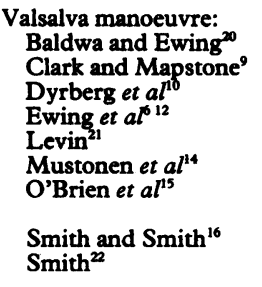 & $\begin{array}{l}\text { Sitting } \\
\text { Sitting } \\
\text { Sitting } \\
\text { Sitting } \\
\text { Semirecumbent } \\
\text { Sitting } \\
\text { Supine/ } \\
\text { semirecumbent } \\
\text { Supine } \\
\text { Supine }\end{array}$ & $\begin{array}{l}15 \mathrm{st} \\
15 \mathrm{~s} \dagger \\
15 \mathrm{s \dagger} \\
15 \mathrm{st} \\
10 \mathrm{s \dagger} \\
15 \mathrm{s \dagger} \\
15 \mathrm{s \dagger} \\
10 \mathrm{s \dagger} \\
10 \mathrm{s \dagger}\end{array}$ & $\begin{array}{l}\text { Mean } 3 \text { manoeuvres } \\
\text { Mean } 3 \text { manoeuvres } \\
1 \text { manoeuvre } \\
\text { Mean } 3 \text { manoeuvres } \\
\text { Higher of } 2 \text { manoeuvres } \\
1 \text { manoeuvre } \\
1 \text { manoeuvre } \\
1 \text { manoeuvre }\end{array}$ & $\begin{array}{l}\text { TR, VR } \\
\text { VR } \\
\text { VR } \\
\text { VR } \\
\text { VR } \\
\text { VR } \\
\text { (max - min) HR, SD HR, } \\
\text { VR } \\
\text { VR } \\
\text { VR }\end{array}$ \\
\hline $\begin{array}{l}\text { Lying to standing: } \\
\text { Clark and Mapstone } \\
\text { Dyrberg et al }{ }^{10} \\
\text { Ewing et al }{ }^{12} \\
\text { O'Brien et } a l^{18} \\
\text { Weiling et } a l^{19}\end{array}$ & $\begin{array}{l}\text { Lying/standing } \\
\text { Lying/standing } \\
\text { Lying/standing } \\
\text { Lying/standing } \\
\text { Lying/standing }\end{array}$ & $\begin{array}{l}40 \text { beats }^{\star} \\
2 \mathrm{~min}^{\star} \\
1 \mathrm{~min}^{\star}\end{array}$ & & $\begin{array}{l}\text { 30:15 ratio windowed } \\
30: 15 \text { ratio } \\
\text { 30:15 ratio windowed } \\
\text { (max }-\min ) \mathrm{HR}, \mathrm{SD} \mathrm{HR} \text {, } \\
(\max / \min ) \mathrm{HR} \\
\max \mathrm{HR}, \min \mathrm{HR}, \\
\text { 30:15 ratio, } \\
\text { 30:15 ratio windowed }\end{array}$ \\
\hline $\begin{array}{l}\text { Normal breathing: } \\
\text { Dyrberg et } a l^{10} \\
\text { Ewing et } a l^{11}\end{array}$ & $\begin{array}{l}\text { Supine } \\
\text { Supine } \\
\text { Supine, sitting, } \\
\text { standing }\end{array}$ & $\begin{array}{l}5 \mathrm{~min} \\
60 \mathrm{~s} \\
255 \mathrm{RR}\end{array}$ & Mean 5 cycles & $\begin{array}{l}\operatorname{mean} R R \\
(\max -\min ) H R \\
S D R R,(\max -\min ) H R, \\
(\max -\min ) R R, \\
\text { mean } \triangle R R, \\
\text { mean } \triangle R^{2} \\
\text { SD RR } \\
(\max -\min ) H R, S D H R, \\
(\max / \min ) H R \\
S D R R\end{array}$ \\
\hline
\end{tabular}

*After standing.

Duration of time pressure was maintained.

HR, heart rate; VR, Valsalva ratio; TR, tachycardia ratio.

only limited information is available on the repeatability of these tests in normal subjects. The repeatability data that are published tend to be presented in different ways, with either $S D$, range, or coefficient of variation $(C V ; S D /$ mean). Table 2 is a summary of the published repeatability data for normal subjects.

As the repeatability of tests in normal subjects is not comprehensively documented, and possible causes for the variability within subjects are rarely considered, the aims of the study were:

(a) To determine the repeatability of a number of electrocardiographically related autonomic function tests already published.

(b) To comment, from the results obtained, on which tests are more likely to lead to repeatable results in clinical use.

(c) To determine the causes of poor repeatability and make recommendations on the way the tests are performed.

\section{Methods}

SUBJECTS

Ten volunteer subjects (eight men) were enrolled in the study. All subjects were well and none had any known autonomic dysfunction or heart complaint. Their ages ranged from 23 to 44.

\section{TEST PROCEDURES}

All the measurements were made in the same room, which was maintained at a constant temperature. One operator made all the measurements on the subjects, who did not eat or drink in the hour preceding the tests. The following analogue data were collected simultaneously during each test. A computer based data aquisition system was used with sampling at $250 \mathrm{~Hz}$. The subject's electrocardiogram was recorded with disposable electrocardiogram chest electrodes to ensure good quality signals, and from this the beat to beat $R R$ intervals were calculated. The respiration pattern during each measurement was recorded using a two channel magnetometer system to give chest and abdominal movements. ${ }^{25}$ From these a calibrated lung volume displacement signal was obtained by summing the two signals in a proportion determined before the test session. The timing of the main section of each test (for example, the beginning and end of 
Table 2 Published repeatability of measurements in normal subjects

\begin{tabular}{|c|c|c|c|c|c|c|c|}
\hline Reference & $\begin{array}{l}\text { No } \\
\text { subj }\end{array}$ & epeat & $\begin{array}{l}\text { Age (yr) } \\
\text { range }\end{array}$ & Measurement & $\begin{array}{l}\text { Mean }(S D) \\
\text { (range) }\end{array}$ & $\begin{array}{l}S D \\
\text { (range) }\end{array}$ & $\begin{array}{l}\mathrm{CV}(\%) \\
\text { (range) }\end{array}$ \\
\hline $\begin{array}{l}\text { Deep breathing: } \\
\text { Ewing et al }{ }^{l^{2}}\end{array}$ & 13 & 10 & & $(\max -\min ) H R$ & $\begin{array}{l}31\left(\min ^{-1}\right) \\
(\text { SD 6) }\end{array}$ & $\begin{array}{l}4\left(\min ^{-1}\right) \\
(3-5)\end{array}$ & - \\
\hline O'Brien et al's & 20 & 5 & $20-35$ & $\begin{array}{l}(\max -\min ) H R \\
(\max / \min ) R R \\
S D H R \\
(\max / \min ) R R\end{array}$ & $\begin{array}{l}= \\
= \\
= \\
= \\
=\end{array}$ & $\begin{array}{l}= \\
= \\
= \\
= \\
= \\
=\end{array}$ & $\begin{array}{l}\overline{16} \\
(7-28) \\
6 \\
(2-9) \\
21 \\
(13-34) \\
8 \cdot 9 \\
-\end{array}$ \\
\hline $\begin{array}{l}\text { Valsalva manoeuvre: } \\
\text { Baldwa and Ewing }\end{array}$ & 12 & 10 & $20-41$ & VR & $1.83(0.37)$ & $\overline{(0.06-0.31)}$ & - \\
\hline Baldwa and Ewing ${ }^{20}$ & 7 & 5 & $52-66$ & VR & $\begin{array}{l}(1 \cdot 22-2 \cdot 48) \\
1 \cdot 49(0 \cdot 18) \\
(1 \cdot 28-1 \cdot 80)\end{array}$ & 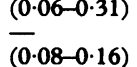 & 二 \\
\hline Ewing et $a l^{12}$ & 19 & $5-10$ & & VR & $1.71(0.35)$ & $\begin{array}{l}0.15 \\
(0.06-0.34)\end{array}$ & 二 \\
\hline Levin $^{21}$ & 30 & 2 & & VR & $\overline{(1.38-2.90)}$ & - & - \\
\hline O'Brien et $a l^{15}$ & 6 & 5 & $20-35$ & $\begin{array}{l}\text { VR } \\
(\max -\min ) H R \\
\text { SD HR }\end{array}$ & $\begin{array}{l}- \\
- \\
-\end{array}$ & $\begin{array}{l}- \\
z \\
-\end{array}$ & $\begin{array}{l}9 \\
(4-16) \\
17 \\
(4-29) \\
21\end{array}$ \\
\hline Smith $^{22}$ & 19 & 2 & & VR & $\overline{\overline{(1 \cdot 23-2 \cdot 78)}}$ & 二 & $15 \cdot 4$ \\
\hline Lying to standing: & 5 & 5 & $21-45$ & $30: 15$ ratio & $\begin{array}{l}1.19 \\
(1.04-1.34)\end{array}$ & - & $5 \cdot 3$ \\
\hline Ewing et $a l^{12}$ & 18 & $5-10$ & & $\begin{array}{l}30: 15 \text { ratio } \\
\text { (windowed) }\end{array}$ & $1.27(0.08)$ & $\begin{array}{l}0.11 \\
(0.06-0.20)\end{array}$ & 9 \\
\hline O'Brien et al ${ }^{15}$ & 6 & 5 & $20-35$ & $\begin{array}{l}\text { 30:15 ratio } \\
\text { (windowed) } \\
\text { (max-min) HR } \\
\text { SD HR }\end{array}$ & $\begin{array}{l}- \\
z \\
-\end{array}$ & $\begin{array}{l}= \\
= \\
=\end{array}$ & $\begin{array}{l}9 \\
(4-16) \\
26 \\
(12-31) \\
24 \\
(10-41)\end{array}$ \\
\hline
\end{tabular}

$\mathrm{HR}$, heart rate; $\mathrm{CV}$, coefficient of variation; VR, Valsalva ratio.

the Valsalva manoeuvre) was recorded with a manually operated switch connected to an input channel.

Each measurement session was a fixed sequence: deep breathing test (subject seated), Valsalva manoeuvre (performed twice and the average taken, subject seated), normal relaxed breathing (subject supine), deep breathing test (subject supine), and lying to standing test. Subjects rested for five minutes supine after the second Valsalva manoeuvre and before the relaxed breathing test in the supine position. The complete sequence was repeated twice during each measurement session. All subjects repeated the session on four separate days over a four week period, giving eight repeat measurements for each test on each subject.

During the deep breathing test subjects breathed regularly at six respiration cycles per minute, with their breathing synchronised to a triangular waveform acting as a visual cue on a display screen. Six cycles (one minute) were collected. During the Valsalva manoeuvre subjects maintained a mouth pressure of $40 \mathrm{~mm} \mathrm{Hg}(5 \cdot 3 \mathrm{kPa})$ for 15 seconds by blowing into a manometer. In the lying to standing test subjects were asked to move from a supine position on a couch to a standing position as quickly as possible. During normal relaxed breathing the subjects were asked to lie quietly and breathe normally, and after the five minute rest period their electrocardiogram was recorded for one minute.

\section{ANALYSIS OF TEST DATA}

For the deep breathing test both maximum (max) and minimum (min) RR intervals were determined for each breathing cycle, and the difference ( $\max -\mathrm{min}) \mathrm{RR}$ and ratio ( $\max / \mathrm{min}$ ) $R R$ calculated. After the $R R$ intervals were converted to instantaneous heart rate (HR) the difference (max-min) HR was also calculated. From these variables the results for the first breathing cycle, the average of breathing cycles two to four, the SD of all RR intervals (SD $R R$ ), and beat to beat changes in RR intervals (SD $\triangle \mathbf{R R}$ ) were calculated. For each Valsalva manoeuvre the ratio of the longest $R R$ interval after the end of the manoeuvre to the shortest $R R$ interval during the manoeuvre was calculated. The Valsalva ratio (VR) was taken as the mean ratio from each pair of consecutive Valsalva manoeuvres. The $30: 15$ ratio is the ratio of the $R R$ intervals following the 30th beat after standing to the RR interval following the 15 th beat after standing. Due to the difficulty in defining exactly the point at which a subject is standing, a windowed 30:15 ratio was also determined (the windows being 10 beats centred on the 30 th and 15 th beats) to allow the use of the shortest and longest $R R$ respectively. The SD $R R$ and the SD $\triangle R R$ were also calculated for normal relaxed breathing. For each of the measurements made while the subjects were deep breathing, the mean and SD of the peak to peak change in respiration were determined from breathing cycles two to four. 
Table 3 Repeatability of measurements obtained in our study

\begin{tabular}{|c|c|c|c|c|}
\hline Test & Mean & $\begin{array}{l}\text { Between } \\
\text { subject SD }\end{array}$ & $\begin{array}{l}\text { Within } \\
\text { subject SD }\end{array}$ & $\begin{array}{l}\text { Ratio } \\
\text { within/between } \\
\text { subject SD }\end{array}$ \\
\hline $\begin{array}{l}\text { Deep breathing sitting: } \\
\text { (max-min) RR (ms) } \\
(\max -\min ) H R\left(\min ^{-1}\right) \\
(\max / \min ) R R 1 \text { st cycle } \\
(\max / \min ) R R \\
\text { SD RR (ms) } \\
\text { SD } \triangle R R(\mathrm{~ms})\end{array}$ & $\begin{array}{c}305 \\
22.8 \\
1.44 \\
1.40 \\
117 \\
77\end{array}$ & $\begin{array}{c}65 \\
5 \cdot 4 \\
0 \cdot 13 \\
0 \cdot 10 \\
25 \\
23\end{array}$ & $\begin{array}{l}46 \\
3.5 \\
0 \cdot 12 \\
0 \cdot 07 \\
16 \\
15\end{array}$ & $\begin{array}{l}0.71 \\
0.65 \\
0.92 \\
0.70 \\
0.64 \\
0.65\end{array}$ \\
\hline $\begin{array}{l}\text { Deep breathing supine: } \\
(\max -\min ) R R\left(\mathrm{~ms}^{2}\right) \\
(\max -\min ) \mathrm{HR}\left(\min ^{-1}\right) \\
(\max / \min ) R R 1 \mathrm{st} \text { cycle } \\
(\max / \min ) R R \\
\text { SD RR }(\mathrm{ms}) \\
\text { SD } \triangle R R(\mathrm{~ms})\end{array}$ & $\begin{array}{c}266 \\
16 \cdot 8 \\
1.34 \\
1.31 \\
102 \\
74\end{array}$ & $\begin{array}{c}55 \\
3.9 \\
0 \cdot 09 \\
0 \cdot 07 \\
19 \\
19\end{array}$ & $\begin{array}{l}51 \\
3 \cdot 2 \\
0 \cdot 12 \\
0 \cdot 06 \\
17 \\
18\end{array}$ & $\begin{array}{l}0.93 \\
0.82 \\
1.33 \\
0.86 \\
0.89 \\
0.95\end{array}$ \\
\hline $\begin{array}{l}\text { Valsalva manoeuvre: } \\
(\max / \min ) \mathrm{RR}(\mathrm{VR})\end{array}$ & 1.92 & 0.38 & $0 \cdot 17$ & 0.45 \\
\hline $\begin{array}{l}\text { Lying to standing: } \\
\text { 30:15 ratio } \\
\text { 30:15 ratio (windowed) }\end{array}$ & $\begin{array}{l}1 \cdot 15 \\
1.36\end{array}$ & $\begin{array}{l}0.13 \\
0.11\end{array}$ & $\begin{array}{l}0 \cdot 11 \\
0.11\end{array}$ & $\begin{array}{l}0.85 \\
1.00\end{array}$ \\
\hline $\begin{array}{l}\text { Relaxed breathing supine: } \\
\text { SD RR (ms) } \\
\text { SD } \triangle \text { RR (ms) }\end{array}$ & $\begin{array}{l}50 \\
45\end{array}$ & $\begin{array}{l}15 \\
16\end{array}$ & $\begin{array}{l}13 \\
10\end{array}$ & $\begin{array}{l}0.87 \\
0.54\end{array}$ \\
\hline
\end{tabular}

HR, heart rate; VR, Valsalva ratio.

\section{STUDY ANALYSIS}

Variability between subjects, between days, and between repeats on the same day was assessed with analysis of variance. The SDs expressing the variability of each measurement in each test were calculated to enable differences between repeatability in each subject to be examined. Also, the average repeatability for each test was determined. To examine for any possible relation between variability of respiration and variability of test results, the deep breathing test was investigated quantitatively. This test was selected because an approach to analysing the respiratory waveform was readily apparent-namely, variability of the peak to peak respiratory pattern. The respiration pattern at the end of the Valsalva manoeuvre was variable and less amenable to quantitative analysis. The repeatability data were normalised to the mean value calculated for each subject, and correlated with mean respiration amplitude and resting $R R$ before the test.

\section{Results}

REPEATABILITY OF TESTS

Table 3 shows the repeatability of results obtained during this study. Variance analysis showed significant between subject variability for all test results $(p<0.005)$. No significant variability occurred between the repeat measurements on different days or between repeats within the same measurement session for any test result. Some tests, however, showed a much smaller within subject variability to between subject variability ratio than others.

Figure 1 shows the within subject variability in each subject for the three most commonly used tests. A few individual results were within the borderline or abnormal ranges of Ewing's definitions. ${ }^{6}$ Four of the results from deep breathing sitting were borderline, and one abnormal. These results occurred in three subjects, two of whom were the oldest in the study group. Only one of the 80 results
Figure 1 Results of three common autonomic function tests: $A$, deep breathing; $B$, Valsalva; and $C$, lying to standing, showing the mean and within subject variability (SD) for each of the 10 subjects. The dashed lines separate the normal range (above) from the abnormal range (below). The deep breathing test has an additional borderline range.
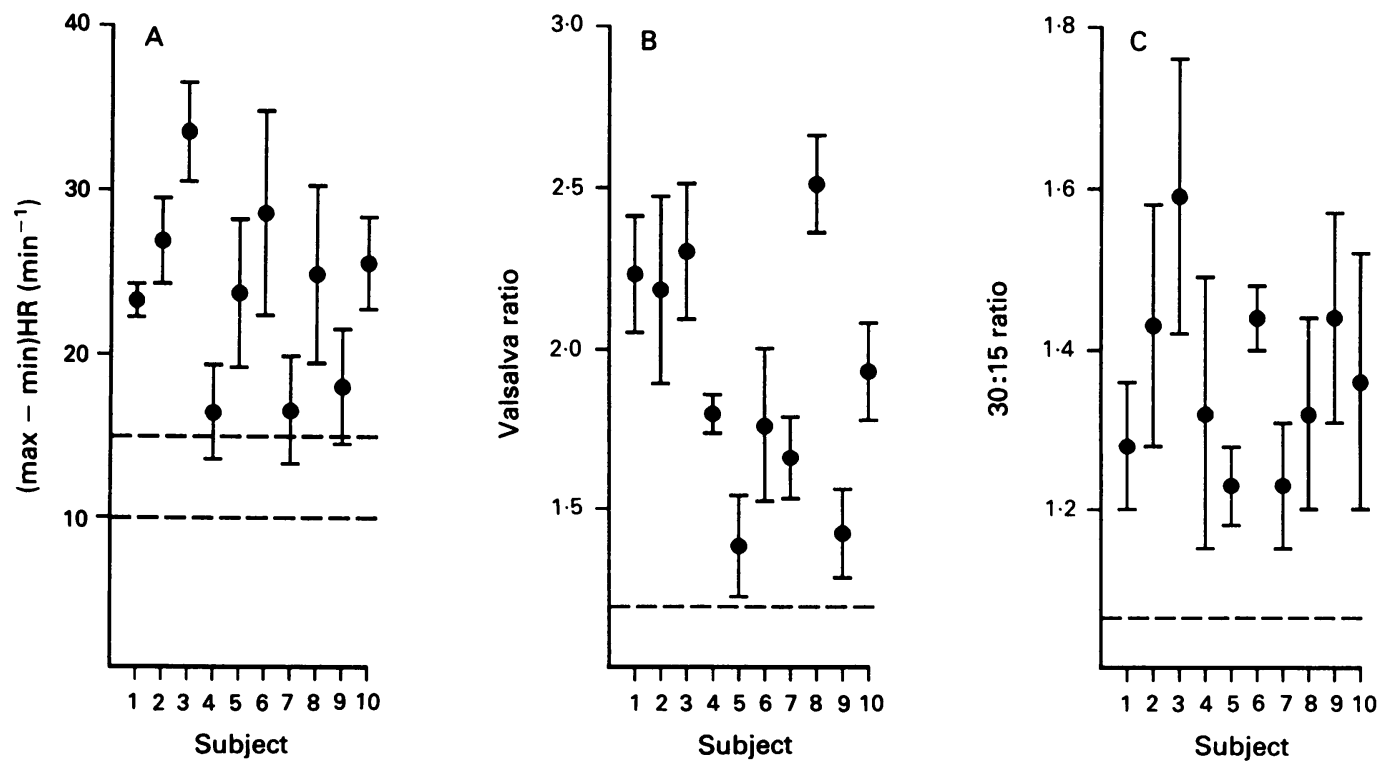
Figure 2 The results of this study: $A$, deep breathing; $B$, Valsalva; and $C$, lying to standing, fell within the normal range for the ages of the subjects. Dotted lines indicate the lower $90 \%$ confidence limits quoted. ${ }^{615} 19$
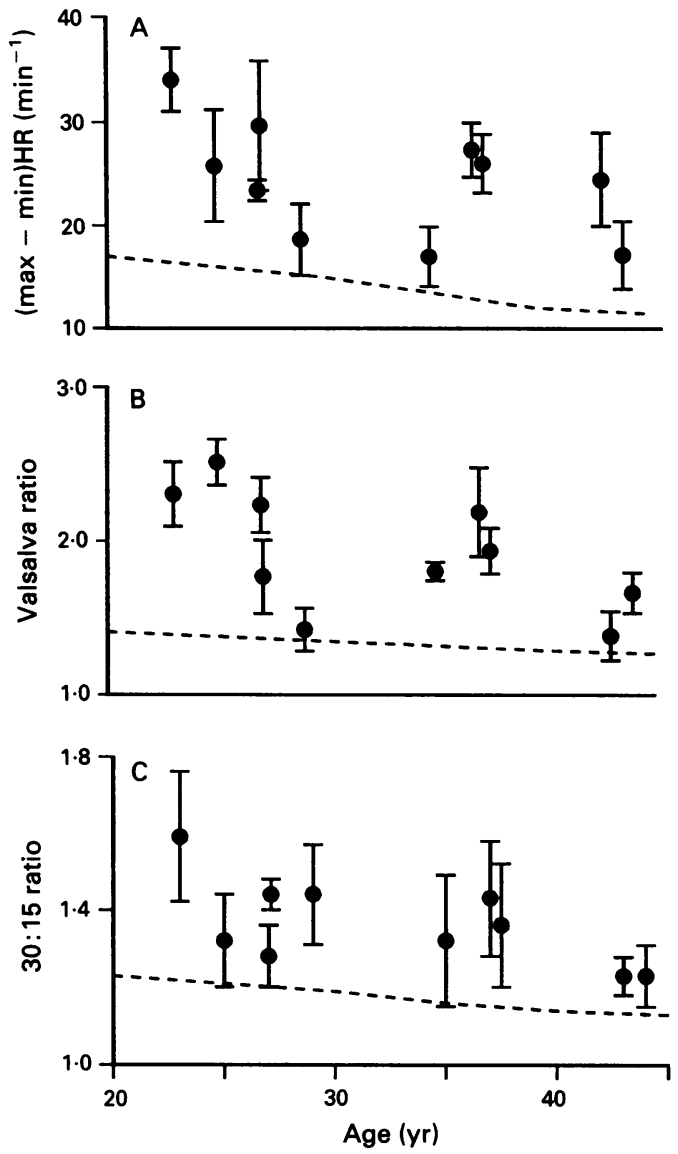

from the Valsalva ratio would be considered abnormal, and this occurred in one of the oldest subjects. All the windowed 30:15 ratios were above the lower limit of the normal range. When repeat measurements were taken into account, all mean results were within normal limits.

Figure 2 plots the results shown in figure 1 against age, confirming that the subjects fall within the normal age related ranges estimated by O'Brien et al ${ }^{15}$ Ewing, ${ }^{6}$ and Weiling et al. ${ }^{19}$

\section{COMPARISON OF TESTS}

Satisfactory tests, which readily distinguish between subjects, are those with a small within subject variability compared with between subject variability. To compare tests, table 3 provides the ratio of within subject $S D$ to between subject SD. The smaller the ratio, the smaller the relative within subject variability and the better the test distinguishes between subjects. Clearly the Valsalva ratio fulfils this criterion the most satisfactorily. This is followed by SD $\triangle R R$ calculated from normal relaxed breathing. The variables calculated while deep breathing in the sitting position have a lower within subject variability compared with between subject variability than those calculated in the supine position. The mean results from three breathing cycles gave more repeatable results than those from a single cycle for the ratio ( $\max / \mathrm{min}) \mathbf{R R}$.

\section{CAUSES OF POOR REPEATABILITY}

When the data from all test procedures were plotted, the most striking qualitative finding was the relation between variability in respiration and variability of the test results. Figure 3 shows two examples from the deep breathing, Valsalva manoeuvre, and lying to standing tests. All clearly show how changes in the respiration pattern influence the results obtained. The pairs of examples for the deep breathing and the Valsalva manoeuvre shown were each taken from measurements on the same day for each subject. The magnetometer data were not normally recorded during the lying to standing test because of artifactual movement of the transducers during standing. Repeat recordings with the transducers fixed securely were obtained subsequently in one of the subjects.

The deep breathing test was selected for further quantitative analysis. For (max-min) $R R$ in this test a relation between an increasing mean value and increasing SD was apparent for eight of the 10 subjects. When the $\mathrm{SD} /$ mean was calculated for each subject and compared with the SD alone, the range of the eight subjects (subjects 2-9) was reduced from 109\% to $53 \%$, and so this normalisation for the mean was undertaken before isolating other independent relations associated with increasing repeat variability.

The poor repeatability in one subject (subject 10) was found to be due to an intermittent change from an atrial to sinus rhythm with decreasing vagal tone on examination of the electrocardiogram. This subject was therefore excluded from further analysis of the causes of poorer repeatability.

For the relation between repeatability and variability of the way the test was performed, fig 4 illustrates how increased variability in test results is associated with increased variability of respiration $(r=0.79, \mathrm{n}=9, \mathrm{p}<0.05)$ : there was also a trend in the relation with the mean resting $R R$ preceding the test, but this was not statistically significant.

\section{Discussion}

A wide range of repeatability data for autonomic function tests in normal people is presented (table 3 ). Only a limited range of repeatability data has been published for autonomic function tests performed on the same occasion and repeated several times. Repeatability data are important because they provide information on quality control necessary for the effective running of a clinical laboratory testing autonomic function. The data provided here could be used as a baseline for such laboratories. It should be noted that different subjects can exhibit different levels of repeatability, and that different tests exhibit different repeatabilities. Such data are relevant when considering the follow up of individual subjects over an extended period.

The repeatability data presented in table 3 also allow comparison between tests and calculations made from these tests. The fact that all test measurements calculated show a significantly different (and lower) repeatability compared with the differences between subjects $(p<0.005)$ confirms that all tests have value. 

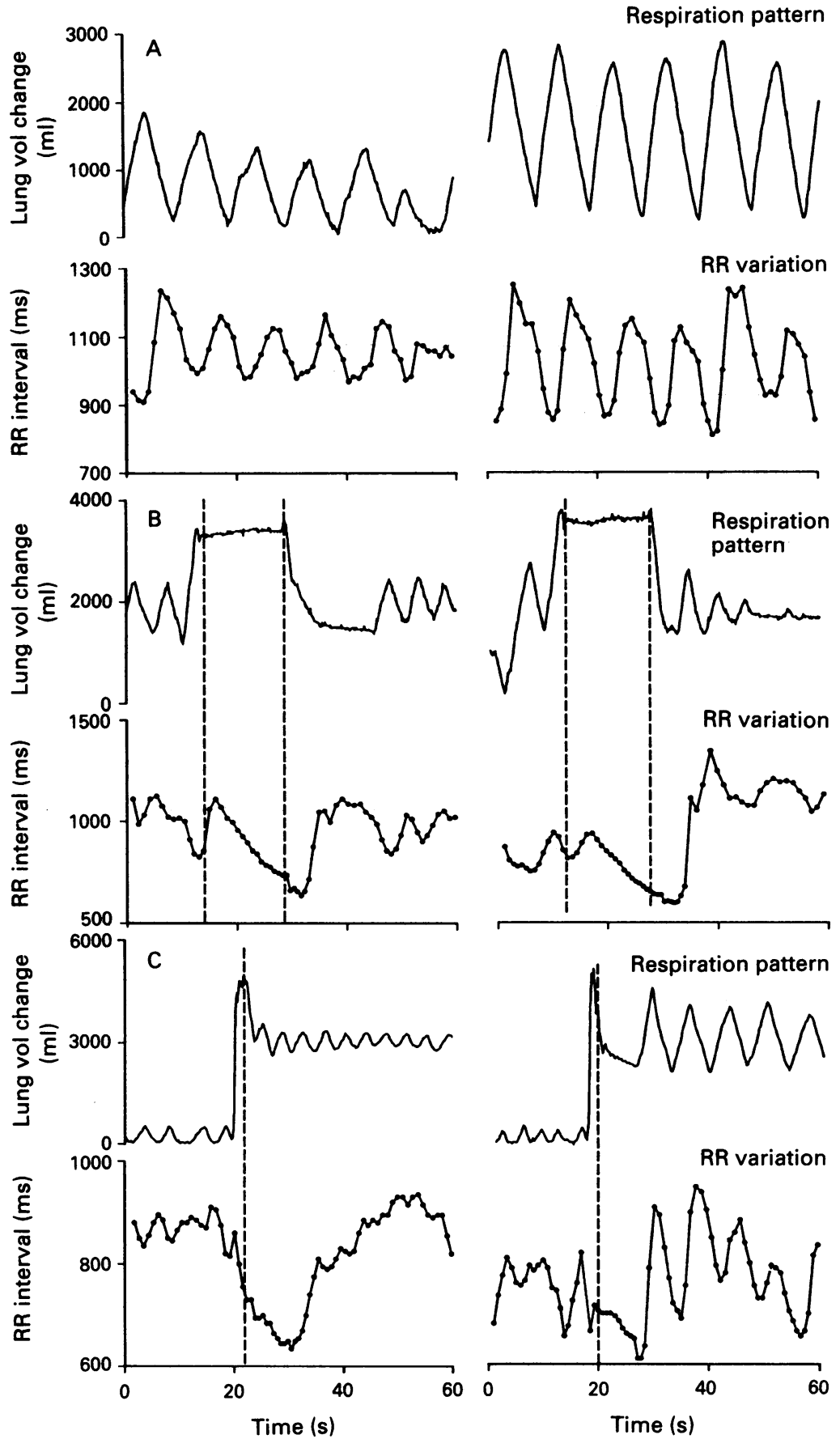

Figure 3 Examples illustrating how changes in respiration pattern alter $R R$ variation and therefore the results obtained for: $A$, deep breathing; $B, V$ alsalva; and $C$, lying to standing tests. Each pair of recordings is taken from the same subject.
The differences, however, were greater in some tests than in others. In particular, the Valsalva ratio stood out as having the lowest repeat variability. The other test with low repeat variability was the relaxed supine breathing test. This test is not usually included in the clinical battery of autonomic function tests, but is easy to perform, with minimum instruction to the subject on how to breathe. During the deep breathing test, the sitting position gave more repeatable results for each variable than the supine position. This is perhaps because of the greater likelihood that subjects breathe more consistently with chest wall movement when sitting rather than with combined (and variable) chest and abdominal movements when supine. Also, as expected, averaging of three respiratory cycles was better than a single cycle measurement.

Even in this study, the repeatability data were valuable in identifying one subject with a heart rhythm that was not fully under vagal control. We were unaware of the atrial rhythm until the poor repeatability, combined with a consistent respiratory pattern, made us take a close look at the electrocardiogram, which had been stored in the computer during the test.

Our study shows that the greatest source of poor repeatability is variation in respiration. Better control of respiration during these tests should be advocated but we do not at this stage recommend respiratory monitoring, which is primarily a research technique. Instead, we suggest that more consistent instruction is given to the subject. For example, the subject could be asked to breathe shallowly after standing in the lying to standing test, or to refrain as much as possible from taking a particularly
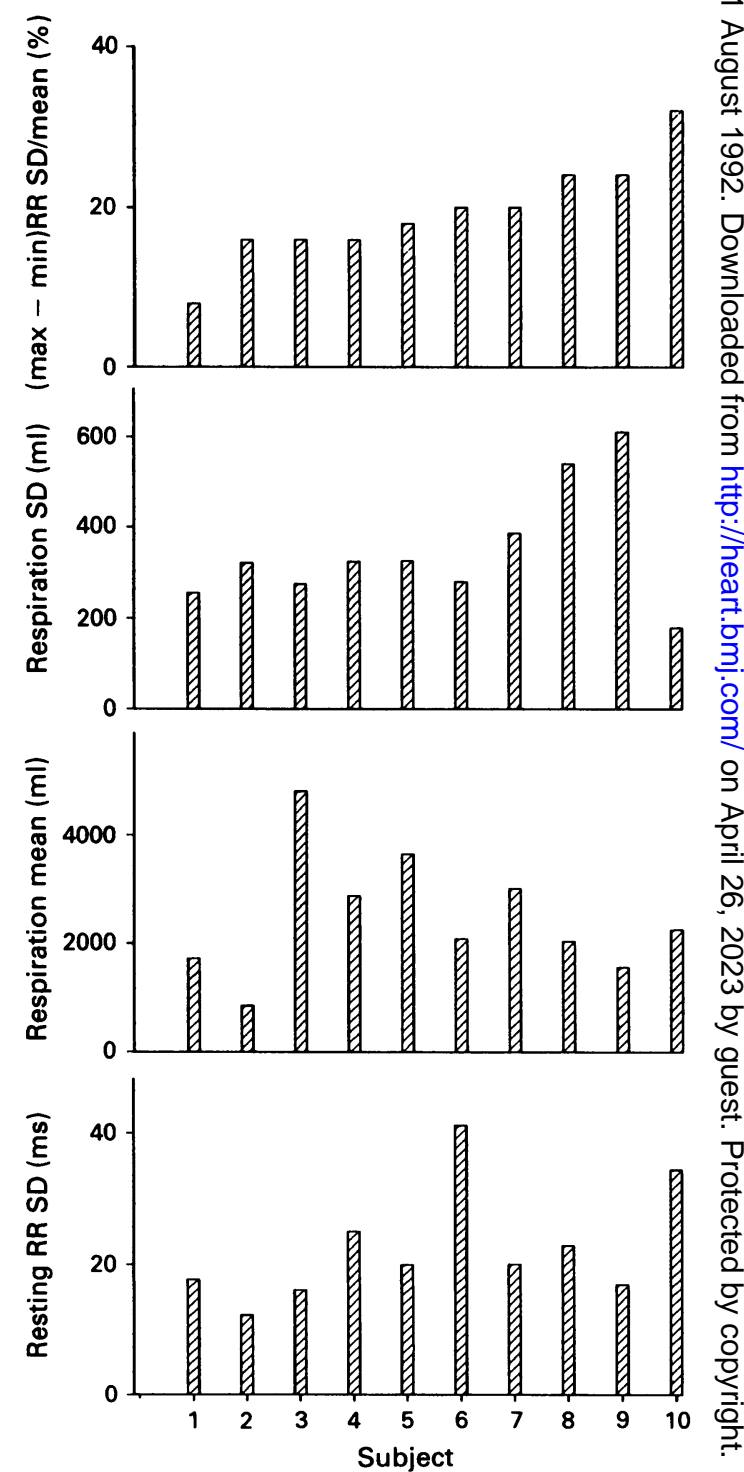

Figure 4 Repeatability of (max-min) RR, SD of respiration, mean of peak to peak respiration depth, and resting $R R$ before the test. 
large gasp after the Valsalva manoeuvre. Before the deep breathing test, subjects could be guided with a simple spirometer to breath a more consistent volume in a given time, and this volume could be noted for future tests.

Our study provides repeatability data in a consistent format for a wide range of autonomic function tests, enables repeatability of different tests to be compared, and documents the relation between repeatability and variability in respiration.

This study was funded by the National Health Service Locally Organised Research Scheme-Regional Research Committee of the Northern Regional Health Authority.

1 Bannister R. Autonomic failure, a textbook of clinical disorders of the autonomic nervous system. 2nd ed. Oxford: Oxford University Press, 1988:267-81.

2 Ewing DJ, Clarke BF. Diagnosis and management of diabetic autonomic neuropathy. BMJ 1982;285:916-8.

3 Wheeler T, Watkins PJ. Cardiac denervation in diabetes. $B M J$ 1973;4:584-6.

4 Fisher BM, Frier BM. Usefulness of cardiovascular tests of autonomic function in asymptomatic diabetic patients. Diabetes Res Clin Prac 1989;6:157-60.

5 Sharpey-Schafer EP, Taylor PJ. Absent circulatory reflexes in diabetic neuritis. Lancet 1960;1:559-62.

6 Ewing DJ. Recent advances in the non-invasive investigation of diabetic autonomic neuropathy. In: Bannister $\mathbf{R}$, ed. Autonomic failure, a textbook of clinical disorders of the autonomic nervous system. 2nd ed. Oxford: Oxford the autonomic nervous system.
University Press, 1988:667-89.

7 Ewing DJ, Campbell IW, Clarke BF. Assessment of cardiovascular effects in diabetic autonomic neuropathy and vascular effects in diabetic autonomic neuropathy and

8 Sampson MJ, Wilson S, Karagiannis P, Edmonds M, Watkins PJ. Progression of diabetic autonomic neuropathy over a decade in insulin-dependent diabetics. Q J Med 1990;278:635-46.

9 Clark CV, Mapstone R. Age-adjusted normal tolerance limits for cardiovascular autonomic function assessment in the elderly. Age Ageing 1986;15:221-9.

10 Dyrberg T, Benn J, Christiansen JS, Hilsted J, Nerup J.
Prevalence of diabetic autonomic neuropathy measured by simple bedside tests. Diabetologia 1981;20:190-4.

11 Ewing DJ, Borsey DQ, Bellavere F, Clarke BF. Cardiac autonomic neuropathy in diabetes: comparison of autonomic neuropathy in diabetes: comparison of 1981;21:18-24.

12 Ewing DJ, Martyn CN, Young RJ, Clarke BF. The value of cardiovascular autonomic function tests: 10 years experience in diabetes. Diabetes Care 1985;8:491-8.

13 Masaoka S, Lev-ran A, Hill LR, Vakil G, Hon EHG. Heart rate variability in diabetes: relationship to age and duration of the disease. Diabetes Care 1985;8:64-8.

14 Mustonen J, Lansimies E, Uusitupa M, Talwar S, Hyodynmaa S, Karkkainen A. Testing of autonomic cardiovascular regulation-methodological considerations. Clin Physiol 1989;9:249-57.

15 O'Brien IAD, O'Hare P, Corrall RJM. Heart rate variability in healthy subjects: effect of age and the derivation of normal ranges for tests of autonomic function. Br Heart 1986;55:348-54.

16 Smith SE, Smith SA. Heart rate variability in healthy subjects measured with a bedside computer-based technique. Clin Sci 1981;61:379-83.

17 Smith SA. Reduced sinus arrhythmia in diabetic autonomic neuropathy: diagnostic value of an age-related normal neuropathy: diagnostic value of

18 Sundkvist G, Almer L-O, Lilja B. Respiratory influence on heart rate in diabetes mellitus. BMJ 1979;1:924-5.

19 Wieling W, van Brederode JFM, de Rijk LG, Borst C Dunning AJ. Reflex control of heart rate in normal subjects in relation to age: a data base for cardiac vagal neuropathy Diabetologia 1982;22:163-6.

20 Baldwa VS, Ewing DJ. Heart rate response to Valsalv manoeuvre: reproducibility in normals, and relation to variation in resting heart rate in diabetics. Br Heart 1977;39:641-4.

21 Levin AB. A simple test of cardiac function based upon the heart rate changes induced by the Valsalva manoeuvre. Am J Cardiol 1966;18:90-9.

22 Smith SA. Diagnostic value of the Valsalva ratio reduction in diabetic autonomic neuropathy: use of an age-related normal range. Diabetic Med 1984;1:295-7.

23 Murray A Ewing DJ, Campbell IW, Neilson JMM, Clarke BF. RR interval variations in young male diabetics $B r$ Heart $J$ 1975;37:882-5.

24 Ewing DJ, Campbell IW, Murray A, Neilson JMM, Clarke BF. Immediate heart-rate response to standing: simple BF. Immediate heart-rate response to standing: simple 1978;i:145-7.

25 Griffiths CJ, Gilmartin JJ, Gibson GJ, Murray A Measurement of chest wall movement: design, performance and clinical use of a four-channel magnetomete system. Clin Phys Physiol Meas 1983;4:363-71. 